\title{
South Korea and Australia: 60 years of diplomatic history, 110 years of human stories
}

Edition 8, 2021

Dr Jay Song, Dr Ryan Gustafsson, Dr Daejeong Choi and Dr Wonsun Shin

DOI: 10.37839/MAR2652-550X8.6

2021 marks the $60^{\text {th }}$ anniversary of diplomatic relations between Australia and South Korea. South Korea is Australia's fourth largest trading partner and the two nations have a shared history as US-allies.

While many official high-level events are being held to celebrate, we researched the little-known state of the South Korean-born population in Australia. Koreans have made a significant contribution to the Australian economy and society, bringing labour, capital, skills, culture, values and modern Korean history with them.

According to the Australian Bureau of Statistics, there were four recorded Koreans in Australia in 1911. Between 1911 and 1971, there were no separate records of the Korean-born Australian population because they were categorised under 'other Asian countries' in country-of-birth data. Until 1991, North and South Korea were categorised together in Australian statistics under the category of 'Korea'. When the two Koreas joined the United Nations as separate sovereign states in 1991, Australia began recording North and South Korean-born populations separately. 
Table 1. Korean-born population, Australia

120000

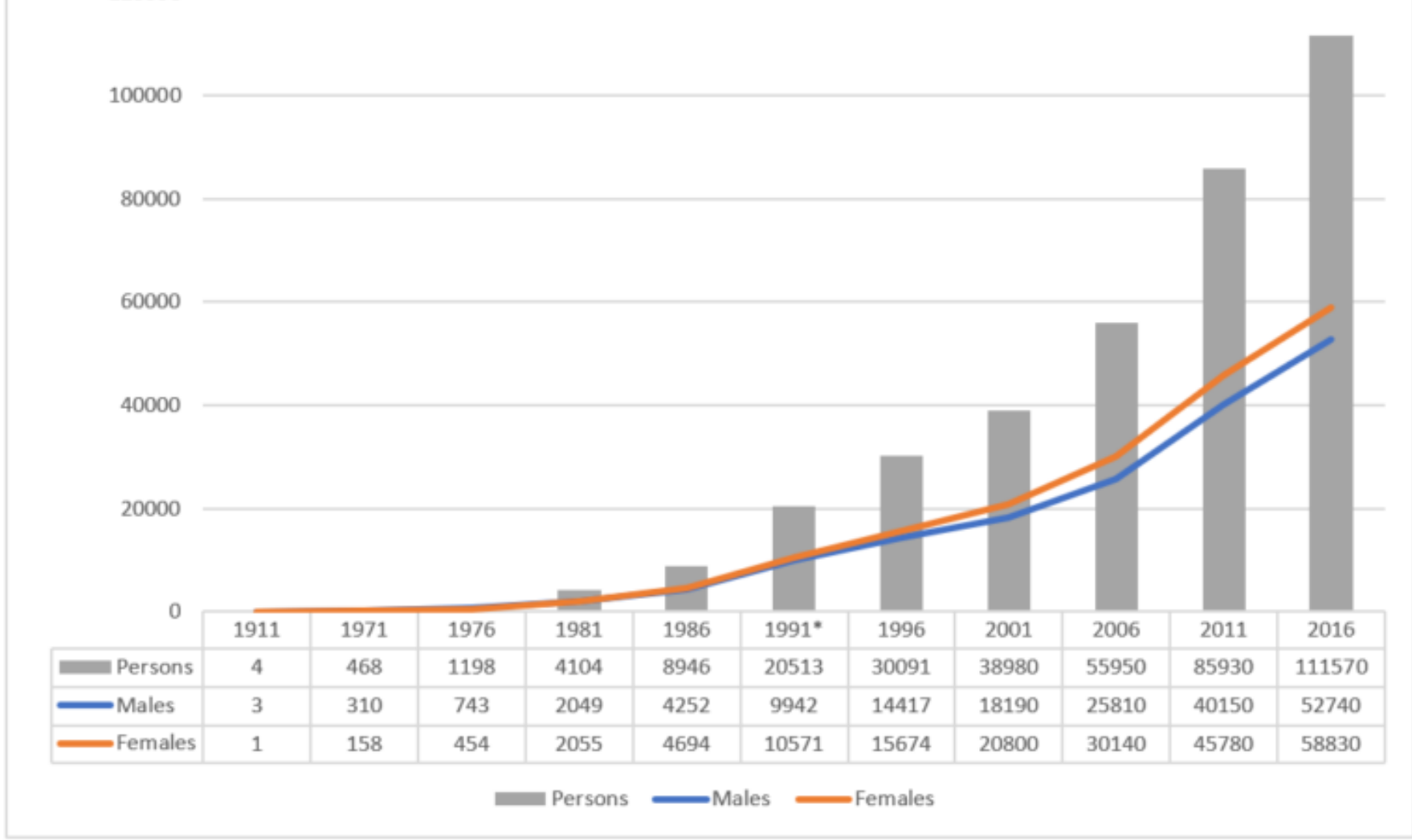

*The records since 1991 are only for South Korean-born populations. [Source: ABS, Historical Population, Country of Birth. Last accessed 21 September 2021]

The 2016 Australian Census shows that 52.5 percent of Korean-born Australians lived in New South Wales (Australia's most populous state), followed by 18.6 percent in Queensland and only 15 percent in Victoria (Australia's second most populous state). Historically, it has been the case that Koreans have mostly resided in New South Wales-between 1976 and 1981 Korean migrants flocked to Sydney in large numbers looking for employment. In the inner Sydney suburb of Redfern there was an informal migrant community centre for Koreans to share information and resources, and the area became a hub for Korean immigrants. The Korean population in New South Wales increased four-fold from 1976 to 1981, doubled again by 1986, and more than doubled again by1991, after South Korea achieved 
democracy and actively pursued liberalisation and globalisation.

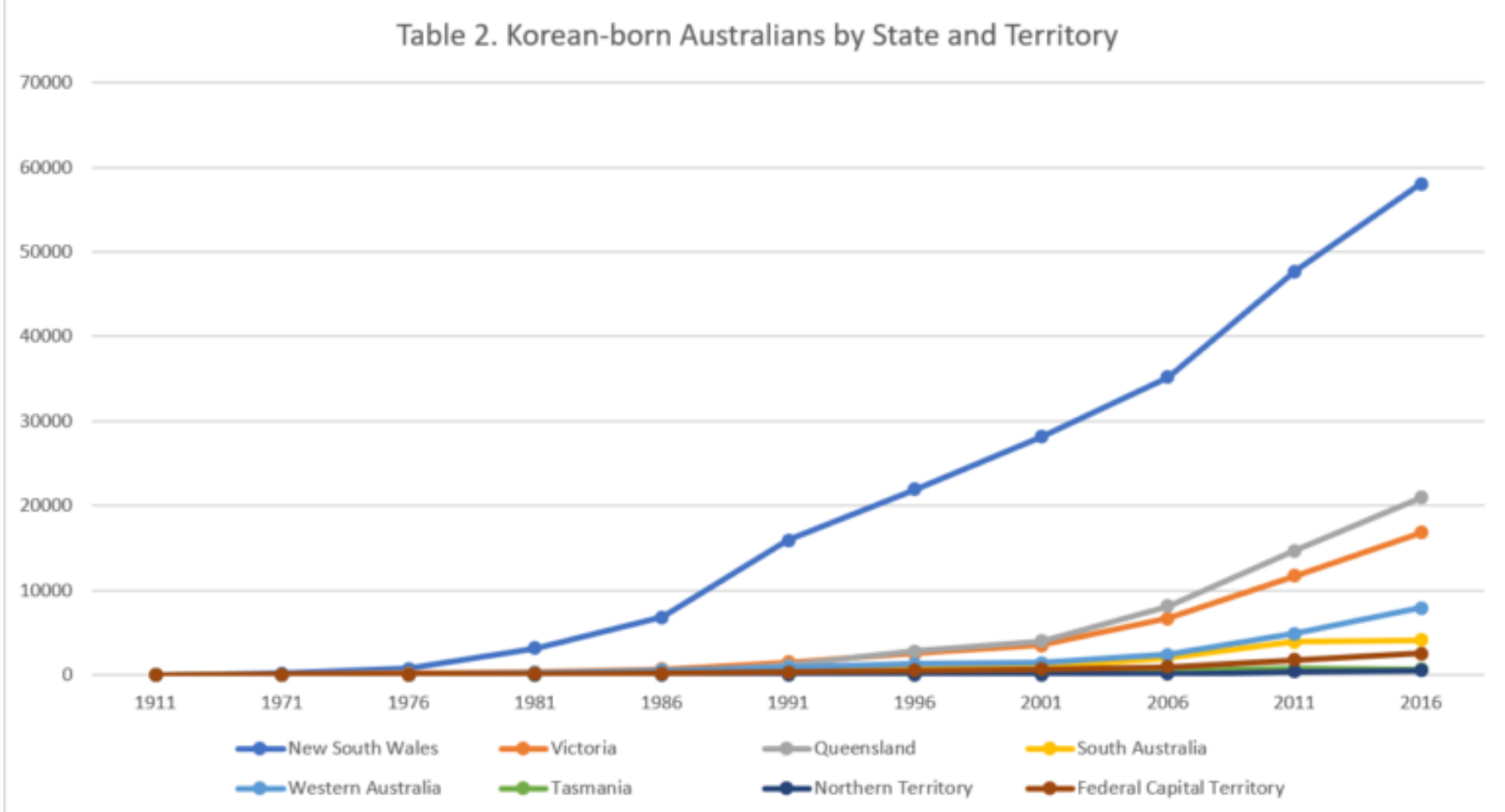

[Source: ABS, Historical Population, Country of Birth. Last accessed 21 September 2021]

\section{Korean Australian survey}

A team of multidisciplinary scholars in migration, media, and business conducted the first nation-wide survey of self-identified Korean Australians between April and September 2021. We gathered 933 responses via personal networks, emails, the mobile communication application widely used among Korean speakers called Kakao, as well as social media such as Facebook. 62.5 percent $(n=583)$ were valid responses with complete and usable data. Along with the national survey, the team also conducted individual interviews with 50 self-identified South Korean Australians.

Almost all (91.3 percent) of valid responses (583) identified themselves as ethnic 
Korean. Just over half (54.2 percent) identified themselves as first-generation Korean Australians who migrated to Australia as adults; 50.5 percent identified as Australian citizens, 47 percent as South Korean and 0.3 percent as North Korean.

Most had lived in Australia for more than a decade: 43.1 percent had lived in Australia for more than 16 years, 23.1 percent had lived in Australia for 11-15 years, 18.8 percent for 6-10 years and 14.3 percent for 1-5 years. Due to the COVID-19 pandemic, only 0.7 percent had lived in Australia less than a year at the time of the survey.

Thirty percent were aged 31-40, 24.7 percent were aged 41-50, 17.3 percent were aged 18-30 and 13.7 percent were aged 51-60. More women (61.2 percent) participated in the survey than men (36.9 percent) while 1.9 percent preferred not to answer or to self-describe their gender. Almost 94 percent were heterosexual while 2.6 percent identified as bisexual, 0.7 percent homosexual, and 0.5 percent as asexual. In terms of their relationship status, 63.6 percent were married, 12.7 percent were in de facto relationships and 17.8 percent were single. A majority (58.3 percent) had children. For those who answered the survey in Korean, 68.5 percent spoke Korean at home, while 30 percent spoke English at home. For those who answered in English, 50.6 percent spoke Korean at home while 44.5 percent spoke English.

\section{Identity, discrimination, culture and Australian community}

A majority (64.1 percent) ranked 'Korean' as their top self-identity, which was more than 'Korean-Australian' (23.1 percent), and 'Asian' (5.3 percent). Even though 50.5 percent held Australian citizenship, only 6.1 percent chose 'Australian' as their top self-identity and 41 percent ranked 'Australian' in the bottom fourth position. This was also evident in our individual interviews in which many participants who had lived in Australia for more than 30-40 years and become Australian citizens in the 
1980s-1990s said they never felt they were 'Australian'. More used the term 'we' when referring to Koreans than when referring to Australians.

Unlike the majority's self-reference as Korean, however, many thought 'belonging' to the Australian community was more important than 'belonging' to the Korean community.

A majority, 59 percent, reported that they had experienced discrimination based on their Korean ethnicity and 15.5 percent reported that they had experienced discrimination based on gender or sexual orientation. Interestingly, amongst those who had experienced gender discrimination, 88.7 percent had also experienced discrimination against their ethnicity, which indicates a significant overlap and intersectionality in sexual and racial discrimination. This needs an in-depth scrutiny and further scholarly investigation.

As Korean Australians connect the two worlds through their social and professional networks, they make a significant contribution to building strong bilateral relations. The majority of Korean Australians went back to Korea frequently, with 16.7 percent returning more than once a year to maintain close contact with their families and relatives there. Approximately 40 percent had extended family members in Australia who also migrated to Australia. While the majority (60.5 percent) worked in Australian multi-cultural work environments, 57.8 percent said their close friendships were largely with other ethnic Koreans.

Korean diasporas remained connected with their Korean identity through food, news, and entertainment. Korean food was eaten almost every day by 66.7 percent of respondents (28.6 percent ate it once a week); and 86.6 percent went Korean grocery shopping once a week or more. A similar proportion, 86.3 percent, consumed Korean news, drama and music, and the vast majority, 82.8 percent, did so more than once a week. They became 'cultural ambassadors' of K-food, K-pop and K-drama as they introduced these elements of Korean culture to others in Australia.

15 respondents, a small subset (2.7 percent) of 583 valid survey respondents were 
Korean adoptees, which is roughly on par with their representation within the wider South Korean-born population in Australia (3.2 percent). Most were under the age of 12 months when adopted.

The most striking differences between adoptees and non-adoptees is that the former were more likely to select 'Australian' as their first ranked identification and use the term 'we' (rather than 'they') when referring to Australians. They were also more likely to report experiencing discrimination due to their ethnic background and on the basis of gender or sexual orientation.

\section{Education, career and life satisfaction}

403 respondents out of 583 valid responses (69 percent) were working at the time of the survey. Most respondents had a very high level of education: 80.8 percent had a Bachelor degree or higher, compared with the Australian average of 24 percent with a Bachelor degree or above, according to the 2016 Census. But this may not be representative of the Korean Australian population as a whole due to the network bias of the researchers, all of whom had doctoral degrees.

When it comes to employment, 32.9 percent of respondents were in full-time employment, 17.3 percent in part-time employment, 13 percent were in casual employment, 19 percent were self-employed, 11.7 percent were unemployed and six percent were retired. In terms of employment sector, 17.5 percent were employed in 'administrative services', 14.9 percent were employed in 'professional services', 14.9 percent in 'others' (not specified) and 9.1 percent in 'accommodation and food services.'

A majority, 59.7 percent of 403 valid responses, were working women. 52 percent were first-generation Korean immigrants. 15.3 percent were skilled migrants. 55.2 percent working Korean Australians reported their personal household income ranged from $\$ 45,001$ to $\$ 120,000$. 
Most respondents reported high levels of satisfaction with their career and life. We created career satisfaction scores by combining the responses on satisfaction with career achievement, career goal progression, and learning opportunity. Almost half (47.1 percent) reported that they were 'satisfied' or 'very much satisfied' with their career (i.e. they rated these elements as 80 or higher out of 100), whereas 13.2 percent reported that they were 'dissatisfied' or 'very much dissatisfied' (i.e. they rated these elements as lower than 60 out of 100). In regard to life satisfaction, 31.8 percent reported that they were 'satisfied' or 'very much satisfied' with their life, whereas 21.3 percent reported that they were 'dissatisfied' or 'very much dissatisfied'. The mean life satisfaction level was slightly lower, rated at 70, than that of the mean career satisfaction, rated at 72 . Life satisfaction was positively correlated with career satisfaction.

Australian citizenship holders tended to rate themselves as happier than noncitizens-there was a strong correlation between citizenship and life satisfaction that could be mutually constitutive. There are two possible theories for this. On the one hand, Korean immigrants who were satisfied with Australian work and life might be more likely to apply for Australian citizenship. On the other, acquiring citizenship could result in higher life satisfaction in Australia. This needs further investigation. Australian citizenship holders reported higher levels of English language competency and had stronger Australian identity compared to non-citizens. There were no significant differences in career and life satisfaction found between male and female workers.

English language proficiency and self-identity were some of the key factors relating to life and career satisfaction, as well as the experience of discrimination at work. The more proficient employees were in English the more likely they were to be satisfied with life and career and identify themselves as Australian; and the less likely they were to perceive workplace culture as discriminating.

Korean identity was not significantly associated with life and career satisfaction. However, the more employees identified themselves as Korean, the more likely they 
were to perceive workplace culture as discriminating. Further, the more they identified themselves as Australian, the more likely they were satisfied with career and life.

\section{Understanding Korea-Australia relations through diasporas}

While the two countries celebrate 60 years of diplomatic relations, our inaugural survey of Korean Australians offers important data on how the two countries are connected and recognised by people who have lived experiences in both. Diplomacy is not only about government-to-government relations-it is also important on the level of people-to-people relations.

There is no single story that can generalise the varied experience of Korean Australians' lives. The current survey is only the first of many longitudinal surveys we plan to carry out every two years in the coming decades. When Korean immigrants came to Australia, they brought not only their labour and capital but also their values, cultures, and modern history. With more Korean Australians entering mainstream Australian society, they will continue to be an important source of understanding in relation to South Korea and build stronger Australia-Korea relations. If Australia wants to learn more about its third biggest export market, it can begin with Korean Australians.

Authors: Dr Jay Song, Dr Ryan Gustafsson, Dr Daejeong Choi and Dr Wonsun Shin.

Acknowledgement: 2021 Korean Australian Survey was funded by the Academy of Korean Studies (AKS-2019-INC-223000X) and the Australia Korea Foundation of the Department of Foreign Affairs and Trade.

Main image: Wooden Hahoe masks (Hahoetal). Traditional ritual Korean mask dance. 